\title{
Psychrotolerant Endophytic Pseudomonas sp. Strains OB155 and OS261 Induced Chilling Resistance in Tomato Plants (Solanum lycopersicum Mill.) by Activation of Their Antioxidant Capacity
}

\author{
Parthiban Subramanian, ${ }^{1}$ Anbazhagan Mageswari, ${ }^{2}$ Kiyoon Kim, ${ }^{1}$ Yi Lee,${ }^{3}$ and Tongmin Sa ${ }^{1}$ \\ ${ }^{1}$ Department of Environmental and Biological Chemistry, Chungbuk National University, Cheongju, Chungbuk, Republic of \\ Korea; ${ }^{2}$ School of Bio Sciences and Technology, VIT University, Vellore, Tamil Nadu 632014, India; ${ }^{3}$ Department of Industrial \\ Plant Science and Technology, Chungbuk National University
}

Submitted 29 January 2015. Accepted 9 June 2015.

\begin{abstract}
Studies on chilling stress damage and its mitigation through microorganisms in members of family Solanaceae is limited, despite their economic importance. We studied chilling stress alleviation in tomato plants colonized by psychrotolerant bacterial strains Pseudomonas vancouverensis OB155-gfp and P. frederiksbergensis OS261-gfp. Log phase cultures of bacterial strains were coated on surface-sterilized seeds (bacterization) before sowing and nonbacterized (control) seeds were coated with sterile bacterial growth medium. All plants were grown at temperatures of 30 and $25^{\circ} \mathrm{C}$ and at the end of 4 weeks, chilling treatment $\left(12\right.$ and $\left.10^{\circ} \mathrm{C}\right)$ was imposed for 1 week on half of the bacterized and control plants. Under normal conditions (30 and $25^{\circ} \mathrm{C}$ ), no significant difference was observed in antioxidant activity, proline accumulation, and expression of cold acclimation genes in tomato leaf tissues of both control and bacterized plants. However, plants exposed to temperatures of 12 and $10^{\circ} \mathrm{C}$ were found to decrease in robustness and nutrient uptake, accompanied by increased membrane damage. Chilling resistance in bacterized plants was evident from reduced membrane damage and reactive oxygen species levels, improved antioxidant activity in leaf tissues, and high expression of cold acclimation genes $L e C B F 1$ and $L e C B F 3$ compared with control plants. Confocal microscopy confirmed effective colonization and intercellular localization of cold-adapted bacterial strains OB155-gfp and OS261-gfp.
\end{abstract}

Abiotic stresses, namely, drought and low temperatures, remain major contributors of agricultural losses and cause more damage to crops than plant pathogens, pests, and weeds (Ruelland et al. 2009). Soils belonging to temperate regions of the world are subjected to intermittent drops in temperatures to less-than-optimal ranges, which causes a regular seasonal freeze-thaw effect, affecting plant growth and other soil biological activities to a large extent (Robertson and Grandy 2006). Such freeze-thaw cycles in the northern hemisphere are expected to increase in severity and frequency throughout the next century (Templer 2012). In addition to the detrimental nature of cold temperatures

Corresponding author: T. Sa; E-mail: tomsa@ chungbuk.ac.kr

*The $\boldsymbol{e}$-Xtra logo stands for "electronic extra" and indicates that two supplementary figures and two supplementary tables are published online.

@ 2015 The American Phytopathological Society on soil nutrient cycles that sustain its fertility, factors such as soil frosts may encourage growth of saprophytic fungi and lead to their dominance in agricultural soils, subsequently increasing root injury in crops (Robertson and Grandy 2006; Templer 2012). Overcoming this cold stress in plants through breeding or genetic engineering is not completely feasible, as the property of cold resistance cannot be caused by regulation or overexpression of a single gene but includes a multitude of signaling cascades and coexpression of several genes acting together to protect the plant against cold (Beck et al. 2004; Fowler and Thomashow 2002).

It is believed that multiple sensors might play a role in perceiving the drop in plant temperature (Miura and Furumoto 2013). The primary cellular responses to cold are cytosol calcium spiking and accumulation of reactive oxygen species (ROS) (Theocharis et al. 2012a). Calcium spiking in the cytosol is linked to activation of cold-related genes (COR) (Miura and Furumoto 2013). Synthesis and accumulation of ROS occurs when different metabolic pathways are uncoupled and electrons with high energy state are transferred to molecular oxygen (Ruelland et al. 2009). Such ROS are produced in the chloroplast, mitochondria, and in the peroxisomes, leading to high levels of physical damage to plant tissues through degradation of cellular components such as nucleic acids, proteins, and lipids (Ruelland et al. 2009; Theocharis et al. 2012a). ROS has been found to be closely related to temperature stresses in plants and their control was reported to enhance tolerance to abiotic stress (Gururani et al. 2013; Suzuki and Mittler 2006).

Beneficial rhizobacteria interact with plants and help them tolerate stress conditions through several direct and indirect mechanisms (Dimkpa et al. 2009; Yang et al. 2009). Prior reports on chilling stress alleviation in plants by use of bacterial inoculants have been studied in members of families Brassicaceae (Chorispora bungeana), Poaceae (Triticum aestivum), and Vitaceae (Vitis vinifera) (Ait Barka et al. 2006; Ding et al. 2011; Fernandez et al. 2012; Mishra et al. 2011; Theocharis et al. 2012b). Despite their worldwide occurrence, several members of family Solanaceae are susceptible to chilling. Commonly available cultivars of tomato, a solanaceous crop, are sensitive to chilling temperatures below $15^{\circ} \mathrm{C}$ (Foolad and Lin 2001; Ploeg and van der Heuvelink 2005). Reports on tomato with regards to chilling injury have often concentrated on postharvest cold-induced damage in tomato fruits, metabolites that induce chilling tolerance, or use of transgenic approaches 
to induce resistance in plants (Duan et al. 2012; Szepesi et al. 2011; Zhang et al. 2011; Zhou et al. 2012). As mentioned earlier, only a handful of reports exist in which studies on plant physiological aspects related to chilling were carried out after application of bacterial inoculants (Ait Barka et al. 2006; Ding et al. 2011; Fernandez et al. 2012; Mishra et al. 2011; Theocharis et al. 2012 b). In the present study, we aimed to study induction of chilling resistance using three aspects of plant physiology, namely, i) improvement of plant growth and robustness under chilling, ii) reduction of chilling-induced damage through reduced ROS content and membrane damage, and iii) improvement of chilling resistance through activation of cold acclimation genes, increase in ROS scavenging metabolites, and activation of antioxidant enzymes.

\section{RESULTS}

Plant growth and nutrient accumulation.

The process of bacterization consisted of soaking surfacesterilized seeds in log phase cultures (cell count $\sim 1 \times 10^{8} \mathrm{cfu} \mathrm{ml}^{-1}$ ) of the isolates for $4 \mathrm{~h}$ and in control treatment surface strerilized seeds were soaked in sterile media. Inoculation of tomato seeds with strains OB155-gfp and OS261-gfp significantly improved plant growth and robustness compared with control plants at the end of chilling treatment as evidenced by increase in plant shoot height, root length and biomass accumulation (Fig. 1; Supplementary Figs. S1 and S2). Furthermore, bacterization of plants resulted in efficient uptake of nutrients from soil, leading to the significant increase in accumulation of nutrients
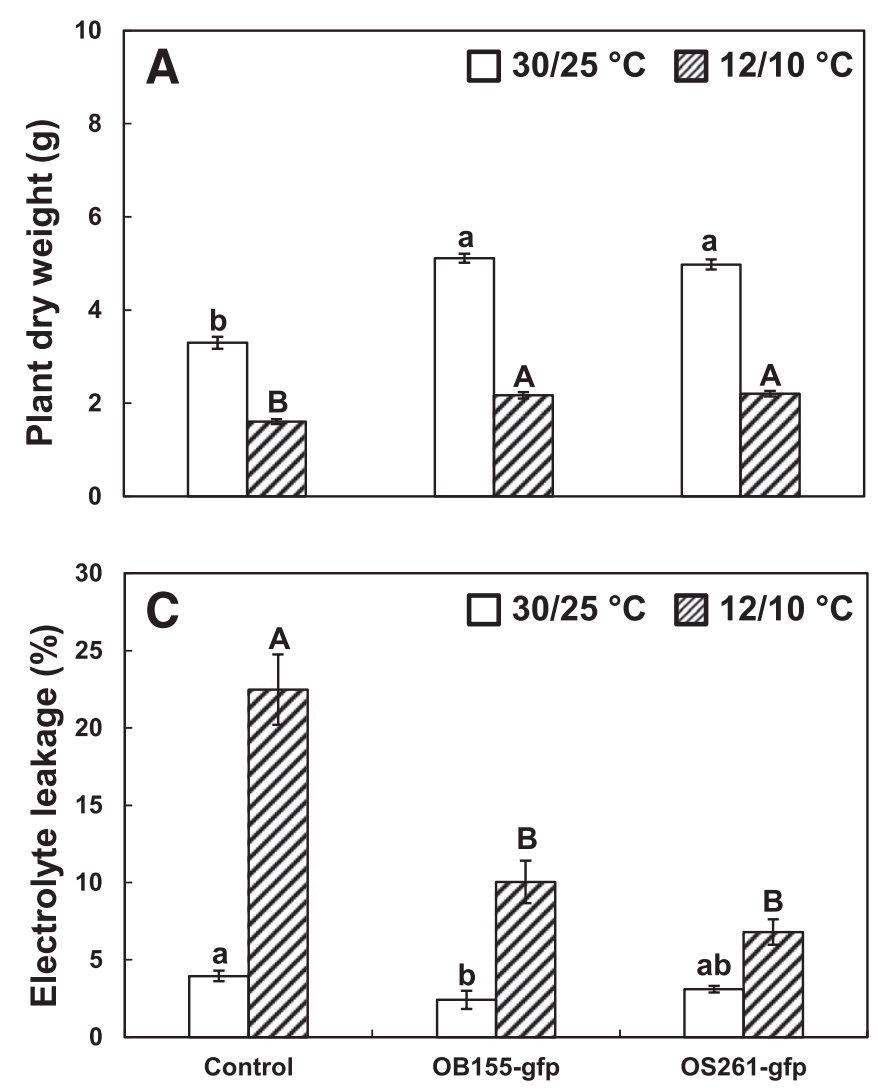

such as nitrogen, phosphorous, calcium, magnesium, and sodium in plant tissues (Table 2).

\section{ROS content and membrane permeability.}

Membrane damage in leaf tissues as a result of chilling stress was significantly reduced in plants inoculated with strains OB155-gfp and OS261-gfp. This can be observed by the significant reduction in the loss of electrolytes from the leaves and low concentrations of the lipid peroxidation product malondialdehyde (MDA) (Fig. 1). Bacterization of plants was also found to decrease ROS content compared with uninoculated control plants, although the decrease was not statistically significant in cases of plants treated with strain OB155-gfp at the end of 1 week of chilling treatment (Fig. 1).

\section{ROS scavenging activity.}

Proline accumulation was significantly higher in leaves of OB155-gfp and OS261-gfp bacterized plants compared with control plants. Treatment with strain OB155-gfp increased proline content by $70.8 \%$ compared with control plants at the end of chilling treatment, whereas the proline content was increased to twice that of the control $(105.3 \%)$ in plants treated with strain OS261-gfp (Fig. 2). In contrast, the treatment OS261gfp failed to show any significant difference in antioxidant enzyme activity, whereas plants treated with OB155-gfp showed a significant increase in activity of enzymes, namely, superoxide dismutase (SOD), catalase (CAT), ascorbate peroxidase (APX), guaiacol peroxidase (POD), and glutathione reductase (GR) at the end of chilling exposure (Fig. 2).
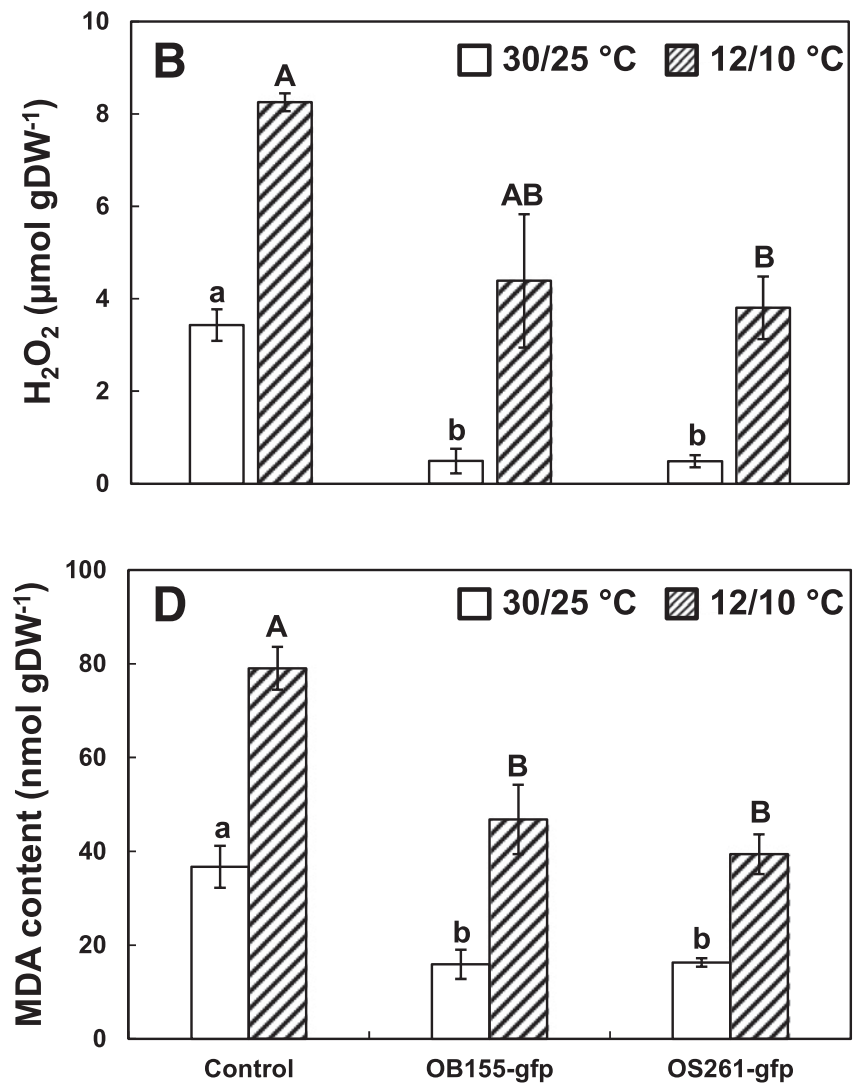

\section{Treatments}

Fig. 1. A, Biomass accumulation in plants, $\mathbf{B}$, reactive oxygen species content, and $\mathbf{C}$ and $\mathbf{D}$, membrane damage in leaves of tomato plants at the end of 5 weeks of growth with 1 week of chilling stress $\left(12\right.$ and $10^{\circ} \mathrm{C}$ day and night temperatures). White bars represent plants maintained at 30 and $25^{\circ} \mathrm{C}$; striped bars, plants exposed to 1 week of chilling treatment at 12 and $10^{\circ} \mathrm{C}$. Letters above the columns show statistical grouping based on Duncan's multiple range test with $P \leq 0.05$. Upper and lower case letters represent independent statistical analysis of data, conducted separately for results from $30 / 25^{\circ} \mathrm{C}$ and $12 / 10^{\circ} \mathrm{C}$ treatments. 
Real-time polymerase chain reaction (PCR) analysis.

Inoculation of strains OB155-gfp and OS261-gfp improved the expression of cold-induced LeCBF1 and $L e C B F 3$ under chilling (Fig. 3). Under normal temperature conditions, there was no significant difference in the expression of the studied genes. However, under chilling temperatures, expression of cold-induced $L e C B F 1$ and $L e C B F 3$ was significantly induced over expression levels in control plants (Fig. 3). LeCBF genes were highly induced in bacterized plants with 5.1- and 5.16-fold expressions (normalized) in the case of LeCBF1 and 6.7- and 11.7-fold expressions (normalized) in $L e C B F 3$, respectively, for strains OB155-gfp and OS261-gfp. Expression of tomato lipoxygenase $($ TomLOX) was observed in bacterized as well as control plants upon exposure to chilling (Fig. 4). However, under
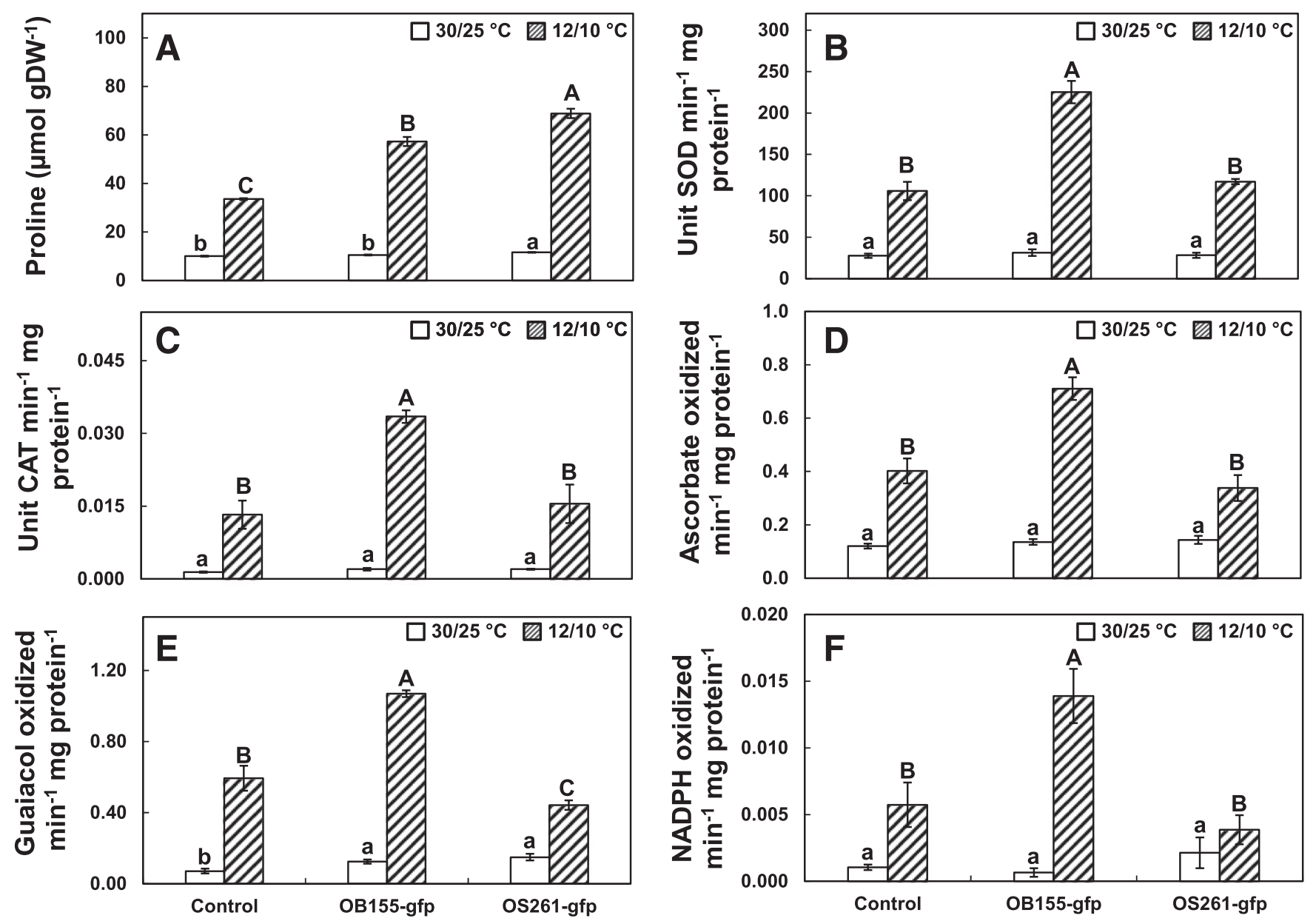

Treatments

Fig. 2. A, Proline content and antioxidant enzyme activity (B, superoxide dismutase [SOD]; C, catalase [CAT]; D, ascorbate peroxidase; E, guaiacol peroxidase; and $\mathbf{F}$, glutathione reductase $)$ in leaves of tomato plants at the end of 1 week of chilling stress $\left(12\right.$ and $\left.10^{\circ} \mathrm{C}\right)$. White bars represent plants maintained at 30 and $25^{\circ} \mathrm{C}$ day and night temperatures; striped bars, plants exposed to 1 week of chilling treatment at 12 and $10^{\circ} \mathrm{C}$. Letters above the columns show statistical grouping based on Duncan's multiple range test with $P \leq 0.05$. Upper and lower case letters represent independent statistical analysis of data, conducted separately for results from $30 / 25^{\circ} \mathrm{C}$ and $12 / 10^{\circ} \mathrm{C}$ treatments.
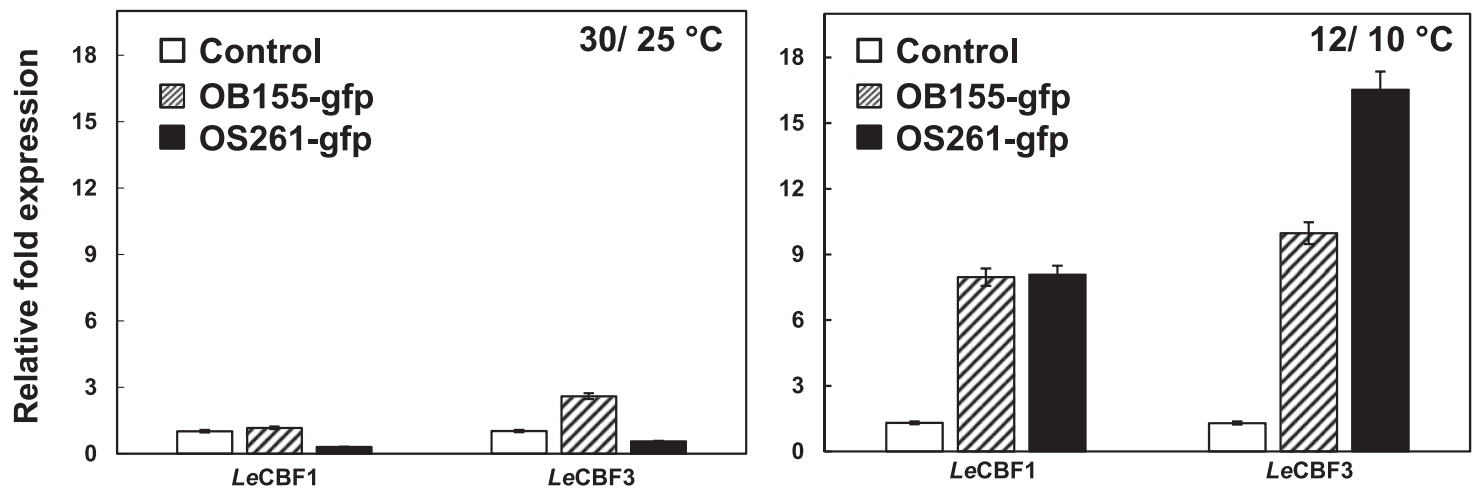

Fig. 3. Expression levels of cold-induced genes $L e C B F 1$ and $L e C B F 3$ at normal conditions and at the end of 1 week of chilling treatment. Results expressed as relative fold expression after normalization with a housekeeping gene. White bars represent control plants; striped bars, plants bacterized with OB155-gfp; black bars, plants bacterized with OS261-gfp. 
normal temperature conditions, TomLOX expression was not induced in control plants but was only expressed in bacterized plants.

\section{Confocal scanning microscopy.}

When roots of harvested tomato plants were observed under confocal laser scanning microscopy (CLSM) to confirm the localization of the green fluorescent protein (GFP)-tagged strains, fluorescent bacterial cells were observed that were absent in uninoculated control plants (Fig. 5). Most of the fluorescent bacterial cells were found to be localized on the surface of the roots. However, several bacteria were also able to move and colonize the intercellular spaces. Both the strains Pseudomonas vancouverensis $\mathrm{OB} 155$-gfp and Pseudomonas frederiksbergensis OS261-gfp efficiently colonized the rhizoplane, moved into root tissues, and localized themselves to intercellular spaces of root tissues (Fig. 5).

\section{DISCUSSION}

With growing concerns over global warming, the world has also observed eccentricities and unpredictable changes in the climatic conditions that have a huge impact on human beings and vegetation ( $\mathrm{Gu}$ et al. 2008; Wang et al. 2011). In North America for example, trends in spring temperatures were not found to consistently increase in years 1982 to 2006. Increases in spring temperatures were found to occur only until the late 1980s or early 1990s, after which the average spring temperatures stabilized or, in several instances, decreased from the early 1990s until 2006 (Wang et al. 2011). Such factors remind us that low temperature as an abiotic factor is not easily predictable and needs to be studied, not only to understand its effect on plant physiological processes but also to sustain agricultural practices. Vast development has been made in understanding perception of cold and its accompanying molecular reactions in plants (Allen and Ort 2001; Chinnusamy et al. 2010; Janská et al. 2010; Ruelland et al. 2009; Theocharis et al. 2012a; Thomashow 2001). Alleviation of abiotic stress in plants, including chilling, through use of bacterial inoculants is not new (Dimkpa et al. 2009; Yang et al. 2009). However, although certain aspects of plant-bacterial interactions have also been studied in detail, the concept of microorganism-plant interaction to alleviate stress is not well understood, except for mechanisms such as bacterial ACC deaminase (Glick et al. 1998).

Chilling stress can impair photosynthesis in plants and reduce its associated parameters, such as chlorophyll content, net photosynthesis, photosystem quantum yield, and stomatal $\mathrm{CO}_{2}$ concentrations (Fernandez et al. 2012; Karabudak et al. 2014; Mishra et al. 2011). This in turn can reduce plant robustness and efficiency of nutrient uptake from the soil. Exposure to low temperature decreased growth and the photosynthestic rate

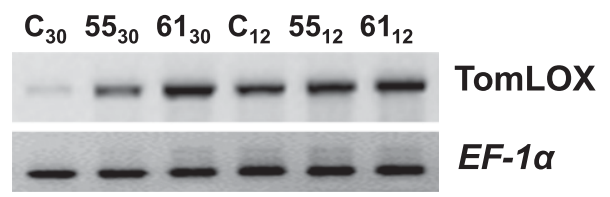

Fig. 4. Semiquantitative analysis of tomato lipoxygenase (TomLOX) gene expression by real-time polymerase chain reaction (PCR) in the leaves of tomato plants. $\mathrm{C}_{30}=$ control plants maintained at 30 and $25^{\circ} \mathrm{C}$ day and night temperatures; $55_{30}=\mathrm{OB} 155$-gfp bacterized plants maintained at 30 and $25^{\circ} \mathrm{C} ; 61_{30}=\mathrm{OS} 261$-gfp bacterized plants maintained at 30 and $25^{\circ} \mathrm{C} ; \mathrm{C}_{12}=$ control plants maintained at 12 and $10^{\circ} \mathrm{C} ; 55_{12}=$ OB155-gfp bacterized plants maintained at 12 and $10^{\circ} \mathrm{C}$; and $61_{12}=\mathrm{OS} 261$-gfp bacterized plants maintained at 12 and $10^{\circ} \mathrm{C}$. EF- $1-\alpha$ gene transcripts were used as internal control for quantitative reverse transcription-PCR products. of grapevine plantlets (Fernandez et al. 2012). In our results, in terms of plant growth promotion, we observed that bacterized plants were robust and showed high biomass content compared with control plants. Moreover, bacterization of plants caused a significant increase in the uptake of nutrients such as nitrogen, phosphorous, potassium, calcium, and sodium. Therefore, inoculation of tomato with strains OB155-gfp and OS261-gfp sustained plant robustness under chilling conditions and continued to improve plant health by improving nutrient uptake.

The process of ROS production commonly occurs in chroloplasts, mitochondria, and peroxisomes of plants both during optimal growth conditions and during stress (Ruelland et al. 2009; Suzuki and Mittler 2006). However, under stress conditions, their levels are dramatically elevated compared with quantities present during optimum conditions of growth. A major impact of chilling-induced ROS damage occurs in cellular membranes and photosynthetic apparatus, resulting in accumulation of fatty acid peroxidation products such as MDA and disruption of membrane integrity leading to leakage of cellular metabolites (Imahori et al. 2008). Levels of MDA are relative to the intensity of oxidative damage and impairment of cell membranes when plants are subjected to low temperatures. In our results, after 1 week of chilling stress, levels of MDA were significantly controlled in bacterized plants compared with control plants that received no bacterial treatment.

When subjected to cold temperatures, accumulation of $\mathrm{H}_{2} \mathrm{O}_{2}$ occurs, which, in huge quantities, is detrimental to plant tissues, as levels of ROS-scavenging enzymes are relatively low. In our studies, we observed a decrease in ROS content in terms of $\mathrm{H}_{2} \mathrm{O}_{2}$ in response to bacterization. Similar reports were made by Ding et al. (2011) and Theocharis et al. (2012b), who found bacterization led to protection of plants against chilling, partly through reduction of $\mathrm{H}_{2} \mathrm{O}_{2}$ content. However, in acclimated or 'primed' plants, the presence of $\mathrm{H}_{2} \mathrm{O}_{2}$ in lower concentrations may trigger the production of antioxidant enzymes and metabolites that scavenge the ROS molecules and help the plant to maintain homeostasis under low-temperature conditions (Theocharis et al. 2012b; Zhou et al. 2012).

Improved chilling-stress tolerance can be related to an increased antioxidant status of plants (Ding et al. 2011). Prior studies have reported the importance of antioxidant enzymes in improving the tolerance of plants to chilling stress (Ding et al. 2011; Theocharis et al. 2012b). Our results indicate a significant increase in activity of antioxidant enzymes SOD, CAT, APX, POD, and GR in chilling-stressed plantlets inoculated with strain OB155-gfp. The expression of these enzymes are crucial for regulation of the cellular ROS levels. Proline is an important organic metabolite that reflects the stress levels in plant tissues when they are exposed to environmental stresses (Delauney and Verma 1993). Prior reports have indicated the increasing trend of proline content in plants when exposed to low temperatures (Ait Barka et al. 2006; Ding et al. 2011; Mishra et al. 2011; Theocharis et al. 2012b). In our experiments, at the end of 1 week of chilling treatment, stress-induced proline levels were consistently high but were significantly higher in inoculated plants compared with noninoculated control plants. Proline has been proposed to be a protective osmolyte, but its physiological role could be extended as an antioxidant molecule that controls photodamage by acting as an electron acceptor (Hare et al. 1998). From these results, it can be observed that strains OB155-gfp and OS261-gfp induced chilling resistance in the plants through regulation of proline and activation of antioxidant enzymes, both of which are parts of the antioxidant system that regulate ROS content in plants. 
CRT repeat binding factors $(\mathrm{CBF})$ are families of transcription factors that act as a regulatory hub during the process of cold acclimation in plants and regulate expression of COR genes (Janská et al. 2010; Ruelland et al. 2009; Theocharis et al. 2012a). Induction of $L e C B F 1$ and $L e C B F 3$ expression in response to chilling has been reported in both chilling-tolerant and -sensitive varieties of tomato, with tolerant varieties showing high levels of expression (Caffagni et al. 2014). In our experiments, we found that, under normal temperature conditions, bacterization of plants did not induce $L e C B F 1$ expression and $L e C B F 3$ was marginally induced by strain OB155-gfp. However, in plants exposed to chilling $\left(12\right.$ and $\left.10^{\circ} \mathrm{C}\right)$, bacterization significantly improved transcript levels of $\mathrm{LeCBF} 1$ and $\mathrm{LeCBF3}$ compared with the control. As mentioned earlier, expression of these two genes were related to the level of tolerance between chilling-tolerant and -sensitive cultivars of tomato, when tolerant varieties exhibited high expression levels (Caffagni et al. 2014). Therefore, their high induction in bacterized plants during our
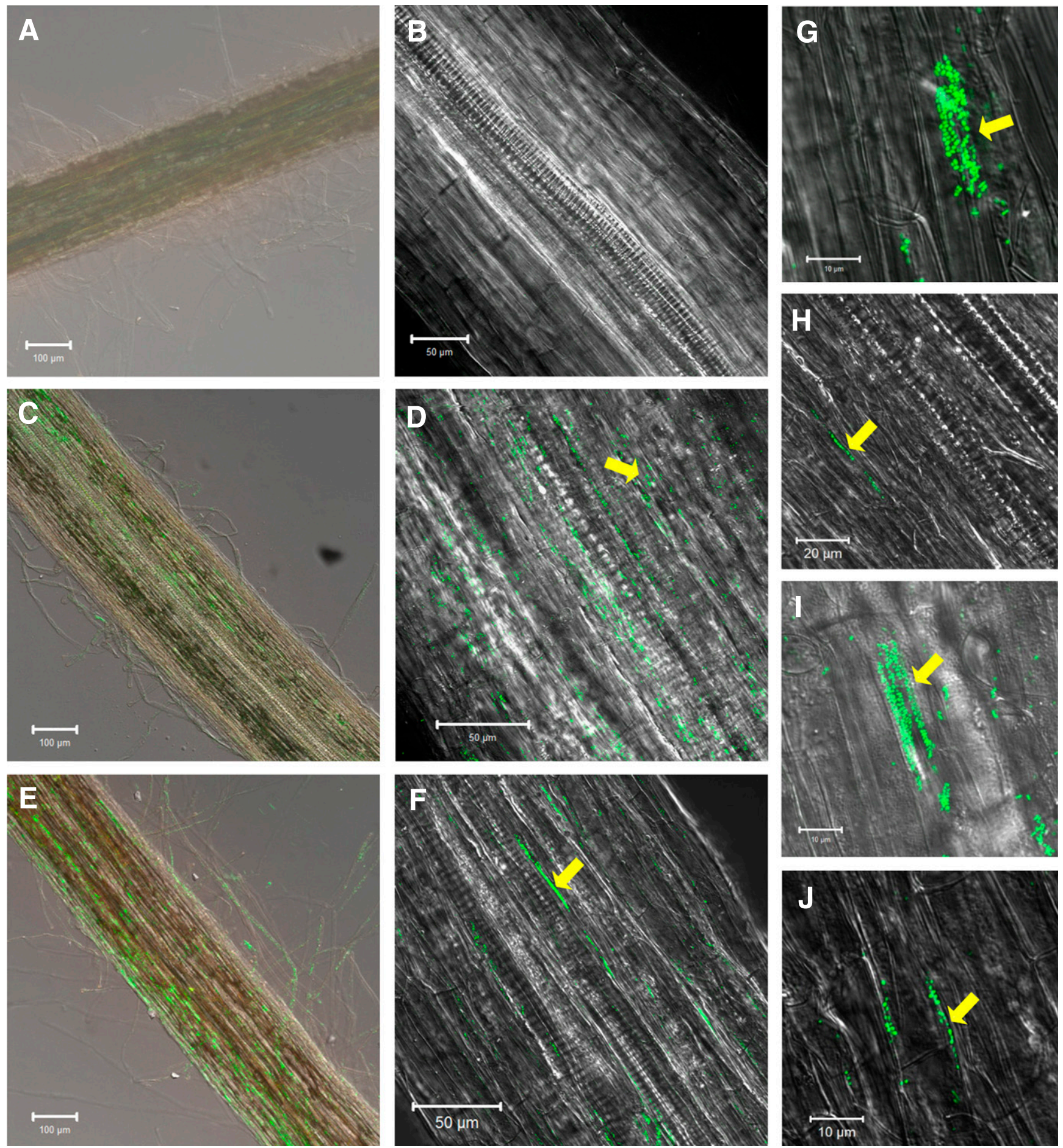

Fig. 5. Confocal microscopy images illustrating the inter- and intracellular colonization of tomato roots by strains OB155-gfp and OS261-gfp. A and B, Control plant root with no fluorescence; $\mathbf{C}$ and $\mathbf{D}$, roots of tomato plants inoculated with strain OB155-gfp; $\mathbf{E}$ and $\mathbf{F}$, roots of tomato plants inoculated with strain OS261-gfp; G, intracellular colonization by strain OB155-gfp; H, strain OB155-gfp colonizing intercellular spaces; I, intracellular colonization by strain OS261-gfp; and J, strain OS261-gfp colonizing intercellular spaces. 
study can be understood as induced tolerance to chilling through bacterization. Induced expression of LOX has been found to contribute to chilling tolerance in grapevine and tomato (Karabudak et al. 2014; Theocharis et al. 2012b). A LOX gene was induced only upon bacterization in the case of grapevine (Theocharis et al. 2012b). However, in the case of tomato, TomLOX was not expressed in plants under normal temperature conditions but was expressed upon cold exposure (Karabudak et al. 2014). Our results also indicated expression of TomLOX in bacterized and control tomato plants upon exposure chilling. However, we also observed that TomLOX was expressed in bacterized plants under normal temperature conditions. Therefore expression of LOX in tomato can occur as a result of abiotic stress and also due to the presence of bacteria in their vicinity. To the best of our knowledge, this is the first time such a phenomenon has been observed in tomato plants.

Bacterial inoculation has been found to result in the induction of defense genes such as endoglucanases and chitinases in plants such as grapevine and sugarcane (Farace et al. 2015; Quecine et al. 2012; Theocharis et al. 2012b). However, these responses can be considered more as "priming" reactions in which less energy is spent by the plant, preparing it for an imminent stress condition. Intriguingly, responses in plants to bacterial inoculation overlap with the responses to abiotic stress (Theocharis et al. 2012a). Therefore, it can be understood that plants initiate a common set of primary responses during initial stages of abiotic stress, pathogen attack, and inoculation of beneficial bacteria, which is a less energy-spending strategy.

Microbe-associated molecular patterns (MAMPs) in plants, recognized through their pattern recognition receptors on the cell surface, occur in response to microbial presence in the vicinity of plants (Felix and Boller 2003). This area of study has been given much importance in the last decade and families of bacterial surface molecules such as flagellins, elongation factors, peptidoglycans, lipopolysaccharides, rhamnolipids, and lipopeptides are a few of the elicitors of a MAMP response. Bacterial cold-shock proteins can act as MAMP elicitors in plants belonging to family Solanaceae and in tobacco (Bittel and Robatzek 2007; Felix and Boller 2003). We had used two psychrotolerant bacterial strains, $P$. vancouverensis OB155-gfp and $P$. frederiksbergensis OS261-gfp, in our experiments and their constitutive synthesis of cold-shock or cold-acclimation proteins to sustain life at low temperatures may have played roles in the development of the cold acclimation response in tomato plants. Studies involving recognition of molecular patterns in plants in response to bacterial secretions can help to understand the exact chain of events that lead to a 'primed' state of plants. This is because several reported MAMPs also involve activation of a primary response similar to that of priming, including activation of defense-related genes and molecules related to oxidative stress.

Both the strains used in the present study were able to effectively colonize root tissues and migrate to intercellular spaces between root cells. This property may have been responsible for their efficacy in inducing plant growth and tolerance in plants under chilling. Malate and oxalate have been reported to be key components of plant root exudates and bacteria that can utilize these organic acids as carbon sources are found to effectively colonize root surfaces (Kost et al. 2014). Strain OB155-gfp can utilize malate but cannot use oxalate as sole carbon source and OS261-gfp was able to effectively utilize malate and oxalate as sole carbon sources (Supplementary Table S2).

On studying the lineage of the strains used in the study, Pseudomonas vancouverensis was initially isolated from resins synthesized by trees and Pseudomonas frederiksbergensis was isolated as a soil bacterium (Andersen et al. 2000; Mohn et al. 1999). Moreover, Pseudomonas vancouverensis has been reported to be closely related to plants, with several strains isolated from leaves and rhizosphere of potato and wheat plants (Someya et al. 2012; Yadav et al. 2014). Species Pseudomonas frederiksbergensis has already been established to be psychrotolerant or psychrophilic in nature (Abdel-Megeed et al. 2010; Prasad et al. 2013).

There have been several reports in which inoculation of bacteria has improved growth and reduced intensity of abiotic stress damage in plants (Dimkpa et al. 2009; Yang et al. 2009). In the present study, bacterization of the plants, using strains OB155gfp and OS261-gfp, resulted in reduced chilling damage, activation of antioxidant enzymes and metabolites, and induction of cold-resistance genes compared with nonbacterized control plants under chilling stress conditions. Though we now have an established knowledge about responses in plants to bacterization, future studies on MAMPs using a metatranscriptomic approach can help us elucidate the whole spectrum of events that occur during microbial inoculation to plants and also help us to get a clear understanding of the concept of plant growth promoting bacteria promoting plant growth and alleviating stress conditions.

\section{MATERIALS AND METHODS}

\section{Strains.}

The selected strains for the current study, Pseudomonas vancouverensis OB155 (KF424309) and Pseudomonas frederiksbergensis OS261 (KF424313), were isolated from agricultural field soil during late winter (January 2012) and were efficiently grown at $5^{\circ} \mathrm{C}$. Both the strains were submitted to the Korean Agricultural Culture Collection (KACC) for public access (Table 1). The strains were found to express multiple plant growthpromoting characteristics at temperatures as low as $5^{\circ} \mathrm{C}$ and to improve chilling tolerance in tomato seedling in our early studies.

\section{GFP-tagging of the strains.}

GFP-tagging was carried out by introducing a Tn5gusAgfpcassette (pFAJ1820) (Xi et al. 1999) into strains OB155 and OS261 by electroporation, using parameters $2.5 \mathrm{kV}, 25 \mu \mathrm{F}, 200 \Omega$ for $5 \mathrm{~ms}$. Transformants were selected on half-strength nutrient agar medium supplemented with kanamycin at $50 \mu \mathrm{g} \mathrm{ml}^{-1}$.

Table 1. Plasmids and strains used in the present study

\begin{tabular}{|c|c|c|}
\hline Plasmid/strain & Genotype or other relevant characteristics & Reference \\
\hline Escherichia coli $\mathrm{S} 17-1$ & Vector for plasmid pFAJ1820 & Xi et al. 1999 \\
\hline Pseudomonas vancouverensis OB155 & $\begin{array}{l}\text { Psychrotolerant plant growth promoting strain (Genbank number: KF424309) } \\
\text { (KACC accession number: KACC92024P) }\end{array}$ & This study \\
\hline Pseudomonas frederiksbergensis OS261 & $\begin{array}{l}\text { Psychrotolerant plant growth promoting strain (Genbank number: KF424313) } \\
\text { (KACC accession number: KACC92040P) }\end{array}$ & This study \\
\hline Pseudomonas vancouverensis OB155-gfp & $\begin{array}{l}\text { Green fluorescent protein (GFP)-tagged mutant representative of } \\
\text { Pseudomonas vancouverensis } \mathrm{OB} 155\end{array}$ & This study \\
\hline Pseudomonas frederiksbergensis OS261-gfp & GFP-tagged mutant representative of Pseudomonas frederiksbergensis OS261 & This study \\
\hline pFAJ1820 & $\begin{array}{l}\text { Plasmid containing a pUT mini-Tn } 5 \text { transposon carrying the kanR gene and } \\
\text { two copies of a gfp gene controlled by the } n p t \text { II promoter }\end{array}$ & Xi et al. 1999 \\
\hline
\end{tabular}


Confirmation for the presence of GFP in the purified transformants was carried out through PCR by amplification using primers YL065 (F) 5'-GCGATGTTAATGGGCAAAAA-3' and YL066 (R) 5'-TCCATGCCATGTGTAATCCT-3'. Reactions for the PCR program were $94^{\circ} \mathrm{C}$ for $2 \mathrm{~min}, 35$ cycles of $94^{\circ} \mathrm{C}$ for $30 \mathrm{~s}$, $56^{\circ} \mathrm{C}$ for $1 \mathrm{~min}$, and $72^{\circ} \mathrm{C}$ for $1 \mathrm{~min}$, followed by $72^{\circ} \mathrm{C}$ for $10 \mathrm{~min}$, and the 650-bp PCR product size confirmed insertion of the $g f p$ cassette (Yim et al. 2014). After PCR confirmation, the relative fluorescence activity of $g f p$-mutant derivatives were measured using a flow cytometer (FACScalibur) equipped with a $15-\mathrm{mW}$, air-cooled argon ion (Ar) laser excitation light source $(488 \mathrm{~nm})$ (Götz et al. 2006). After selection of one colony each, representative of OB155 and OS261, respectively, colony appearance, cell morphologies, and growth rate of the $g f p$-derivative and wild type were compared.

\section{Plant experiments.}

Growth conditions. Tomato seeds, Solanum lycopersicum cv. Mill., were surface-sterilized with $2 \%$ sodium hypochlorite containing $0.02 \%$ Tween 20 for $5 \mathrm{~min}, 70 \%$ ethanol for $1 \mathrm{~min}$ followed by rinsing three times with sterile deionized water, 3 min for every wash. Aliquots $(100 \mu \mathrm{l})$ of water from the final wash were spread on nutrient agar to ensure efficiency of sterilization. Bacterization consisted of seed treatment by soaking surface-sterilized seeds in sterile media or log phase cultures (cell count approximately $1 \times 10^{8} \mathrm{CFU} \mathrm{ml} \mathrm{m}^{-1}$ ) of the isolates for $4 \mathrm{~h}$. Bacterized and nonbacterized tomato seeds were germinated and grown in $500 \mathrm{~g}$ of Biosangto-Mix soil substrate (Heung Nong Co., Ltd.) containing 65 to $70 \%$ coco peat, 15 to $20 \%$ peat moss, 8 to $10 \%$ perlite, and macronutrient (milligrams per milliliter: $\mathrm{NH}_{4}-\mathrm{N}, 80$ to $100 ; \mathrm{NO}_{3}-\mathrm{N}, 150$ to 200; available $\mathrm{P}_{2} \mathrm{O}_{5}, 230$ to $330 ; \mathrm{K}_{2} \mathrm{O}, 80$ to 120 , pH 5.5 to 6.5 ; moisture content 50 to $60 \%$, and water holding capacity 35 to $40 \%$ ) in a growth chamber (DS 54 GLP, DASOL Scientific Co., Ltd.) for 4 weeks at 30 and $25^{\circ} \mathrm{C}$ day and night temperatures (light: $200 \mu \mathrm{mol} \mathrm{m} \mathrm{m}^{-2} \mathrm{~s}^{-1}$ ). After germination, the pots were watered with half-strength Hoagland's nutrient solution and sterile distilled water on alternative days. At the end of 4 weeks, half of the control and bacterized plants were moved to another plant growth chamber maintained at 12 and $10^{\circ} \mathrm{C}$ day and night temperatures. This chilling exposure was imposed for a period of 1 week and, at the end of the week, plants were harvested (Theocharis et al. 2012b).

Plant growth. Improvement of plant growth was analyzed by measuring the plant height, root length, and plant biomass content after harvesting the plants at the end of the 1-week chilling treatment. On the day of harvesting, plant height was measured and root lengths were measured after carefully washing the harvested roots in running water, followed by blotting them dry. To measure biomass accumulation, harvested roots and shoots of individual plants were combined and dried in a hot-air oven at $70^{\circ} \mathrm{C}$ for $48 \mathrm{~h}$, at the end of which, the dry weight was measured. The total nitrogen content of shoots and roots of plants was assayed using a Kjeltec analyzer (Kjeltec 2300 Analyzer unit). Available phosphorus was measured by vanadate-molybdate method and $\mathrm{Ca}, \mathrm{Mg}, \mathrm{Na}$, and $\mathrm{K}$ were measured after extraction, using inductively coupled plasma optical emission spectrometry.

\section{ROS content and membrane permeability.}

Hydrogen peroxide content in leaves was evaluated according to the protocols of Theochariset al. (2012b). Membrane permeability was studied in terms of electrolyte leakage and MDA content in the leaves. To study electrolyte leakage, six fully growth leaves were rinsed, blotted dry, and placed in conical centrifuge tubes containing $15 \mathrm{ml}$ of double-distilled water. The tubes were incubated for $24 \mathrm{~h}$ at $25^{\circ} \mathrm{C}$. After incubation, the conductivity $(E 1)$ was measured with a conductivity meter. Subsequently, the tissue was placed in a $100^{\circ} \mathrm{C}$ water bath for $30 \mathrm{~min}$ and, then, cooled to $25^{\circ} \mathrm{C}$, and a second conductivity measurement was made (E2). The electrical conductivity of deionized water was also measured (E0). The percent relative electrolyte leakage (REL) was calculated as follows (Mishra et al. 2011):

$$
\mathrm{REL}=(E 1-E 0) /(E 2-E 0) \times 100
$$

Malondialdehyde content was measured using the protocols of Taulavuoriet al. (2001). Leaf tissues $(0.4 \mathrm{~g})$ were homogenized in liquid nitrogen with a mortar and pestle and the homogenized tissue powder was suspended in $6 \mathrm{ml}$ of $0.1 \%$ trichloroacetic acid (TCA). The mixture was centrifuged at $10,000 \times g$ for $5 \mathrm{~min}$ and the supernatant was divided into two tubes with 1-ml aliquots in each tube. The first tube received $4 \mathrm{ml}$ of $20 \%$ (wt/vol) TCA, and the second tube received $4 \mathrm{ml}$ of $20 \%$ (wt/vol) TCA containing $0.5 \%$ thiobarbituric acid. The solution mixtures were heated to $95^{\circ} \mathrm{C}$ for $30 \mathrm{~min}$ and, then, were quickly cooled in an ice bath. Centrifugation was carried out at $10,000 \times g$ for $10 \mathrm{~min}$ after cooling and absorbance of supernatant was read at 440, 532, and $600 \mathrm{~nm}$. Malondialdehyde content was calculated using its extinction coefficient $155 \mathrm{mM}^{-1} \mathrm{~cm}^{-1}$.

\section{ROS scavenging activity.}

Proline content in leaves was estimated according to the protocols of Mishra et al. (2011), with minor modifications. Leaf tissues $(0.5 \mathrm{~g})$ were homogenized in $5 \mathrm{ml}$ of $3 \%$ sulfosalicylic acid and the homogenate was centrifuged at $12,000 \times g$ for $10 \mathrm{~min}$. The reaction mixture consisted of $2 \mathrm{ml}$ of the supernatant, $2 \mathrm{ml}$ of acid ninhydrin, and $2 \mathrm{ml}$ of glacial acetic acid. The mixture was incubated in a water bath maintained at $100^{\circ} \mathrm{C}$ for $30 \mathrm{~min}$ and the reaction was stopped by cooling in an ice bath. Toluene ( $4 \mathrm{ml}$ ) was used to extract the colored component present in the aqueous solution, and the absorbance of the extracted toluene measured at $520 \mathrm{~nm}$. Proline content was calculated using a standard curve made using known concentrations of proline.

To measure antioxidant enzyme activity, fresh leaf samples (approximately $500 \mathrm{mg}$ ) were ground to powder in liquid nitrogen using a mortar and pestle and were stored at $-80^{\circ} \mathrm{C}$.

Table 2. Nutrient accumulation in tomato plants after growth and 1 week of chilling treatment

\begin{tabular}{|c|c|c|c|c|c|c|}
\hline Treatments & $\mathbf{N}$ & $\mathbf{P}$ & $\mathbf{C a}$ & Mg & $\mathbf{K}$ & $\mathrm{Na}$ \\
\hline \multicolumn{7}{|c|}{30 and $25^{\circ} \mathrm{C}$ day and night temperatures } \\
\hline Control & $681.6 \pm 4.8 \mathrm{a}$ & $165.3 \pm 1.6 \mathrm{a}$ & $29.1 \pm 2.3 \mathrm{a}$ & $24 \pm 1 \mathrm{a}$ & $64.2 \pm 1.5 \mathrm{a}$ & $14.4 \pm 0.9 \mathrm{a}$ \\
\hline OB155-gfp & $1,098.5 \pm 55.2 b$ & $276.7 \pm 3.2 b$ & $51.7 \pm 0.5 b$ & $35.8 \pm 2.8 b$ & $102.8 \pm 6.8 b$ & $21.1 \pm 0.8 b$ \\
\hline OS261-gfp & $1,021.4 \pm 14.9 b$ & $308.3 \pm 6.7 \mathrm{c}$ & $51.8 \pm 2.8 b$ & $30.8 \pm 1.9 \mathrm{ab}$ & $101.5 \pm 7.3 b$ & $19.1 \pm 1.6 b$ \\
\hline \multicolumn{7}{|c|}{12 and $10^{\circ} \mathrm{C}$ day and night temperatures } \\
\hline Control & $243.5 \pm 5.1 \mathrm{a}$ & $97.9 \pm 2.4 \mathrm{a}$ & $13.8 \pm 1.2 \mathrm{a}$ & $8.5 \pm 0.7 \mathrm{a}$ & $25.5 \pm 1 \mathrm{a}$ & $5.3 \pm 0.3 \mathrm{a}$ \\
\hline OB155-gfp & $353.9 \pm 0.8 \mathrm{c}$ & $144.6 \pm 1.7 b$ & $20.1 \pm 0.6 b$ & $12.6 \pm 0.7 b$ & $42.5 \pm 4.3 b$ & $9.1 \pm 1.3 b$ \\
\hline OS261-gfp & $328.7 \pm 2.9 b$ & $156.2 \pm 1.1 \mathrm{c}$ & $20.3 \pm 0.7 b$ & $11.7 \pm 0.5 b$ & $36.5 \pm 3.3 \mathrm{ab}$ & $8.9 \pm 0.8 b$ \\
\hline
\end{tabular}

${ }^{a}$ Measured in milligrams per plant, values indicate mean \pm standard error $(n=3)$ and different letters on values within each column denote significant difference based on Duncan's multiple range test $(P<0.05)$. 
Powdered samples $(0.5 \mathrm{~g})$ were homogenized on ice in $10 \mathrm{ml}$ of $50 \mathrm{mM}$ potassium phosphate buffer ( $\mathrm{pH} 7.8$ ) containing $1 \%$ (wt/vol) polyvinylpyrrolidone and were kept at $4{ }^{\circ} \mathrm{C}$ for $10 \mathrm{~min}$. The homogenate was centrifuged at $4,000 \times g$ for $15 \mathrm{~min}$ at $4^{\circ} \mathrm{C}$. The supernatant was considered as the enzyme extract and was temporarily stored at $4^{\circ} \mathrm{C}$ before enzyme assays. Activities of CAT (EC 1.11.1.6), SOD (EC 1.15.1.1), APX (EC 1.11.1.11), and POD (EC 1.11.1.7) in the enzyme extract were determined spectrophotometrically. (Ding et al. 2011). GR (EC 1.8.1.7) activity was taken as a measure of oxidation of NADPH, calculated using the extinction coefficient of $6.224 \mathrm{mM}^{-1} \mathrm{~cm}^{-1}$ at $340 \mathrm{~nm}$ (Gururani et al. 2013).

\section{Quantitative and semiquantitative real time PCR analysis.}

Total RNA was extracted from tomato leaves, using a Plant RNeasy mini kit (Qiagen), and cDNA synthesized using the Superscript III first strand synthesis system (Invitrogen). SYBR Green master mix (Bio-Rad) was used for quantification in an iQ5 optical system (Bio-Rad). The primers for this study are listed in Supplementary Table S1. The following protocol was used for amplification of $L e C B F 1$ and $L e C B F 3: 95^{\circ} \mathrm{C}$ for $10 \mathrm{~min}$, followed by $95^{\circ} \mathrm{C}$ for $15 \mathrm{~s}, 60^{\circ} \mathrm{C}$ for 1 min (Caffagni et al. 2014). Obtained data were analyzed using the $\Delta \Delta \mathrm{Ct}$ (cycle threshold) method. PCR amplification for TomLOX was performed at $94^{\circ} \mathrm{C}$ for $1 \mathrm{~min}, 55^{\circ} \mathrm{C}$ for $2 \mathrm{~min}, 72^{\circ} \mathrm{C}$ for $3 \mathrm{~min}$ for 35 cycles (Karabudak et al. 2014). The products were loaded on $1 \%$ (wt/vol) agarose gel containing $0.5 \mu \mathrm{g} \mathrm{ml}^{-1}$ ethidium bromide and was observed using a ChemiDoc XRS system (Bio-Rad). All samples were amplified in triplicate independent cDNA samples per treatment and the mean value was considered. Elongation factor 1- $\alpha(E F-1-\alpha)$ was used as the internal control for normalization of data from PCR as it is the best housekeeping gene in chilling conditions (Caffagni et al. 2014).

\section{Preparation of plant samples for confocal microscopy.}

Fresh plant samples (roots) removed from the plants inoculated with OB155-gfp and OS261-gfp were washed in sterile distilled water and were blotted dry. Sections of surface-sterilized roots, made using sterile scalpel blades, were used to check the endophytic colonization by the inoculated strains. The samples were mounted, using sterile glycerol as mounting medium, under a coverslip. Microscopic observations were performed using the Leica TCS SP2 confocal system (Leica Microsystems Heidelberg $\mathrm{GmbH}$ ) equipped with an Ar laser (gfp: excitation, $488 \mathrm{~nm}$; emission filter BP, 500 to 530). Image acquisitions were carried out using $\times 10$ and $\times 40$ objectives (N.A. approximately 0.75$)$ and were processed using the Zen software package (version 2.5.1227a).

\section{Statistical analysis.}

Randomized block design was used for the controlled-condition plant experiments. Data from the results were normalized, were subjected to analysis of variance and mean significant difference were compared by Duncan multiple range test at $P \leq 0.05$, using SAS package 9.1.3 service pack 4 .

\section{ACKNOWLEDGMENTS}

This research was supported by the Basic Science Research Program through the National Research Foundation of Korea (NRF), funded by the Ministry of Education, Science and Technology (2015R1A2A1A05001885).

\section{LITERATURE CITED}

Abdel-Megeed, A., Aboul-Soud, M. A. M., Mueller, R., Rudolf, F. A., and Al-Deyab, S. S. 2010. Purification and biochemical characterization of recombinant alcohol dehydrogenase from the psychrophilic bacterium Pseudomonas frederiksbergensis. J. Polym. Environ. 18:617-625.
Ait Barka, E., Nowak, J., and Clément, C. 2006. Enhancement of chilling resistance of inoculated grapevine plantlets with a plant growth-promoting rhizobacterium, Burkholderia phytofirmans strain PsJN. Appl. Environ. Microbiol. 72:7246-7252.

Allen, D. J., and Ort, D. R. 2001. Impacts of chilling temperatures on photosynthesis in warm-climate plants. Trends Plant Sci. 6:36-42.

Andersen, S. M., Johnsen, K., Sørensen, J., Nielsen, P., and Jacobsen, C. S. 2000. Pseudomonas frederiksbergensis sp. nov., isolated from soil at a coal gasification site. Int. J. Syst. Evol. Microbiol. 50:1957-1964.

Beck, E. H., Heim, R., and Hansen, J. 2004. Plant resistance to cold stress: Mechanisms and environmental signals triggering frost hardening and dehardening. J. Biosci. 29:449-459.

Bittel, P., and Robatzek, S. 2007. Microbe-associated molecular patterns (MAMPs) probe plant immunity. Curr. Opin. Plant Biol. 10:335-341.

Caffagni, A., Pecchioni, N., Francia, E., Pagani, D., and Milc, J. 2014 Candidate gene expression profiling in two contrasting tomato cultivars under chilling stress. Biol. Plantarum 58:283-295.

Chinnusamy, V., Zhu, J. K., and Sunkar, R. 2010. Gene regulation during cold stress acclimation in plants. Methods Mol. Biol. 639:39-55.

Delauney, A. J., and Verma, D. P. S. 1993. Proline biosynthesis and osmoregulation in plants. Plant J. 4:215-223.

Dimkpa, C., Weinand, T., and Asch, F. 2009. Plant-rhizobacteria interactions alleviate abiotic stress conditions. Plant Cell Environ. 32: 1682-1694.

Ding, S., Huang, C. L., Sheng, H. M., Song, C. L., Li, Y. B., and An, L. Z. 2011. Effect of inoculation with the endophyte Clavibacter sp. strain Enf12 on chilling tolerance in Chorispora bungeana. Physiol. Plant. 141: 141-151.

Duan, M., Feng, H. L., Wang, L. Y., Li, D., and Meng, Q. W. 2012. Overexpression of thylakoidal ascorbate peroxidase shows enhanced resistance to chilling stress in tomato. J. Plant Physiol. 169:867-877.

Farace, G., Fernandez, O., Jacquens, L., Coutte, F., Krier, F., Jacques, P., Clément, C., Barka, E. A., Jacquard, C., and Dorey, S. 2015. Cyclic lipopeptides from Bacillus subtilis activate distinct patterns of defence responses in grapevine. Mol. Plant Pathol. 16:177-187.

Felix, G., and Boller, T. 2003. Molecular sensing of bacteria in plants. The highly conserved RNA-binding motif RNP-1 of bacterial cold shock proteins is recognized as an elicitor signal in tobacco. J. Biol. Chem. 278: 6201-6208

Fernandez, O., Theocharis, A., Bordiec, S., Feil, R., Jacquens, L., Clément, C., Fontaine, F., and Barka, E. A. 2012. Burkholderia phytofirmans PsJN acclimates grapevine to cold by modulating carbohydrate metabolism. Mol. Plant-Microbe Interact. 25:496-504.

Foolad, M. R., and Lin, G. Y. 2001. Relationship between cold tolerance during seed germination and vegetative growth in tomato: analysis of response and correlated response to selection. J. Am. Soc. Hortic. Sci. 125:679-683

Fowler, S., and Thomashow, M. F. 2002. Arabidopsis transcriptome profiling indicates that multiple regulatory pathways are activated during cold acclimation in addition to the CBF cold response pathway. Plant Cell 14:1675-1690.

Glick, B. R., Penrose, D. M., and Li, J. 1998. A model for the lowering of plant ethylene concentrations by plant growth-promoting bacteria. J. Theor. Biol. 190:63-68.

Götz, M., Gomes, N. C. M., Dratwinski, A., Costa, R., Berg, G., Peixoto, R., Mendonça-Hagler, L., and Smalla, K. 2006. Survival of gfp-tagged antagonistic bacteria in the rhizosphere of tomato plants and their effects on the indigenous bacterial community. FEMS (Fed. Eur. Microbiol. Soc.) Microbiol. Ecol. 56:207-218.

Gu, L., Hanson, P. J., Post Dale, W. M., Kaiser, P., Yang, B., Nemani, R., Pallardy, S. G., and Meyers, T. 2008. The 2007 eastern US spring freeze: Increased cold damage in a warming world. Bioscience 58: 253-262.

Gururani, M. A., Upadhyaya, C. P., Baskar, V., Venkatesh, J., Nookaraju, A., and Park, S. W. 2013. Plant growth-promoting rhizobacteria enhance abiotic stress tolerance in Solanum tuberosum through inducing changes in the expression of ROS-scavenging enzymes and improved photosynthetic performance. J. Plant Growth Regul. 32:245-258.

Hare, P. D., Cress, W. A., and Van Staden, J. 1998. Dissecting the roles of osmolyte accumulation during stress. Plant Cell Environ. 21:535-553.

Imahori, Y., Takemura, M., and Bai, J. 2008. Chilling-induced oxidative stress and antioxidant responses in mume (Prunus mume) fruit during low temperature storage. Postharvest Biol. Technol. 49:54-60.

Janská, A., Marsík, P., Zelenková, S., and Ovesná, J. 2010. Cold stress and acclimation-What is important for metabolic adjustment? Plant Biol 12:395-405

Karabudak, T., Bor, M., Özdemir, F., and Türkan, I. 2014. Glycine betaine protects tomato (Solanum lycopersicum) plants at low temperature by 
inducing fatty acid desaturase7 and lipoxygenase gene expression. Mol. Biol. Rep. 41:1401-1410.

Kost, T., Stopnisek, N., Agnoli, K., Eberl, L., and Weisskopf, L. 2014. Oxalotrophy, a widespread trait of plant-associated Burkholderia species, is involved in successful root colonization of lupin and maize by Burkholderia phytofirmans. Front Microbiol 4:421.

Mishra, P. K., Bisht, S. C., Ruwari, P., Selvakumar, G., Joshi, G. K., Bisht, J. K., Bhatt, J. C., and Gupta, H. S. 2011. Alleviation of cold stress in inoculated wheat (Triticum aestivum L.) seedlings with psychrotolerant pseudomonads from NW Himalayas. Arch. Microbiol. 193:497-513.

Miura, K., and Furumoto, T. 2013. Cold signaling and cold response in plants. Int. J. Mol. Sci. 14:5312-5337.

Mohn, W. W., Wilson, A. E., Bicho, P., and Moore, E. R. 1999. Physiological and phylogenetic diversity of bacteria growing on resin acids. Syst. Appl. Microbiol. 22:68-78.

Ploeg, A., and van der Heuvelink, E. 2005 Influence of sub-optimal temperature on tomato growth and yield: a review. J Hortic. Sci. Biotechnol. 80:652-659.

Prasad, S., Pratibha, M. S., Manasa, P., Buddhi, S., Begum, Z., and Shivaji, S. 2013. Diversity of chemotactic heterotrophic bacteria associated with arctic cyanobacteria. Curr. Microbiol. 66:64-71.

Quecine, M. C., Araújo, W. L., Rossetto, P. B., Ferreira, A., Tsui, S., Lacava, P. T., Mondin, M., Azevedo, J. L., and Pizzirani-Kleiner, A. A. 2012. Sugarcane growth promotion by the endophytic bacterium Pantoea agglomerans 33.1. Appl. Environ. Microbiol. 78:7511-7518.

Robertson, G. P., and Grandy, A. S. 2006. Soil system management in temperate regions. Pages 27-39 in Biological Approaches to Sustainable Soil Systems. N. T. Uphoff, ed. CRC Press. Boca Raton, FL, U.S.A.

Ruelland, E., Vaultier, M. N., Zachowski, A., and Hurry, V. 2009. Cold signalling and cold acclimation in plants. Pages 35-150 in: Advances in Botanical Research. J.-C. Kader and M. Delseny eds. Academic Press, London.

Someya, N., Morohoshi, T., Ikeda, T., Tsuchiya, K., and Ikeda, S. 2012. Genetic diversity and ecological evaluation of fluorescent pseudomonads isolated from the leaves and roots of potato plants. Microbes Environ. 27:122-126.

Suzuki, N., and Mittler, R. 2006. Reactive oxygen species and temperature stresses: a delicate balance between signaling and destruction. Physiol. Plant. 126:45-51.

Szepesi, A., Gemes, K., Orosz, G., Peto, A., Takacs, Z., Vorak, M., and Tari, I. 2011. Interaction between salicylic acid and polyamines and their possible roles in tomato hardening process. Acta. Biol. Szegediensis. 55: $165-166$.

Taulavuori, E., Hellström, E. K., Taulavuori, K., and Laine, K. 2001. Comparison of two methods used to analyse lipid peroxidation from Vaccinium myrtillus (L.) during snow removal, reacclimation and cold acclimation. J. Exp. Bot. 52:2375-2380.

Templer, P. H. 2012. Changes in winter climate: soil frost, root injury, and fungal communities. Plant Soil 353:15-17.

Theocharis, A., Bordiec, S., Fernandez, O., Paquis, S., Dhondt-Cordelier, S., Baillieul, F., Clément, C., and Barka, E. A. 2012b. Burkholderia phytofirmans PsJN primes Vitis vinifera L. and confers a better tolerance to low nonfreezing temperatures. Mol. Plant-Microbe Interact. 25:241-249.

Theocharis, A., Clément, C., and Barka, E. A. 2012a. Physiological and molecular changes in plants grown at low temperatures. Planta 235:1091-1105.

Thomashow, M. F. 2001. So what's new in the field of plant cold acclimation? Lots! Plant Physiol. 125:89-93.

Wang, X., Piao, S., Ciais, P., Li, J., Friedlingstein, P., Koven, C., and Chen, A. 2011. Spring temperature change and its implication in the change of vegetation growth in North America from 1982 to 2006. Proc. Natl. Acad. Sci. U.S.A. 108:1240-1245.

Xi, C., Lambrecht, M., Vanderleyden, J., and Michiels, J. 1999. Bi-functional gfp- and gusA-containing mini-Tn5 transposon derivatives for combined gene expression and bacterial localization studies. J. Microbiol. Methods 35:85-92.

Yadav, S., Yadav, S., Kaushik, R., Saxena, A. K., and Arora, D. K. 2014. Genetic and functional diversity of fluorescent Pseudomonas from rhizospheric soils of wheat crop. J. Basic Microbiol. 54:425-437.

Yang, J., Kloepper, J. W., and Ryu, C. M. 2009. Rhizosphere bacteria help plants tolerate abiotic stress. Trends Plant Sci. 14:1-4.

Yim, W. J., Kim, K. Y., Lee, Y. W., Sundaram, S. P., Lee, Y., and Sa, T. M. 2014. Real time expression of ACC oxidase and PR-protein genes mediated by Methylobacterium spp. in tomato plants challenged with Xanthomonas campestris pv. vesicatoria. J. Plant Physiol. 171:1064-1075.

Zhang, X., Shen, L., Li, F., Meng, D., and Sheng, J. 2011. Methyl salicylateinduced arginine catabolism is associated with up-regulation of polyamine and nitric oxide levels and improves chilling tolerance in cherry tomato fruit. J. Agric. Food Chem. 59:9351-9357.

Zhou, J., Wang, J., Shi, K., Xia, X. J., Zhou, Y. H., and Yu, J. Q. 2012. Hydrogen peroxide is involved in the cold acclimation-induced chilling tolerance of tomato plants. Plant Physiol. Biochem. 60:141149. 